\title{
A CASE OF CYST OF THE URACHUS
}

\author{
WITH NOTES ON URACHAL AND SO-CALLED \\ "ALLANTOIC CYSTS"
}

\author{
BY \\ ALBAN DORAN, F.R.C.S. \\ SURGEON TO THE SAMARITAN FREE HOSPITAL
}

Received February lst-Read May 24th, 1898

EARLy in the autumn of $1897 \mathrm{I}$ operated on a case of cystic abdominal tumour which presented certain remarkable features. After much deliberation I am of opinion that the tumour arose from the urachus. Cysts attributed to that structure have been repeatedly described, and interesting monographs on the subject have been written by Wutz, Freer, Byron Robinson, and other writers, mostly German and American.

Before considering urachal cysts in general I will relate my own experience.

E. S-, aged 59, married thirty-one years (five children, two abortions, last confinement twenty-two years ago), a patient of Dr. Blamey, of Penryn, Cornwall, was admitted into the Samaritan Free Hospital on September 28th, 1897. The patient had enjoyed perfect health till three years previously, when she suffered from bronchitis 
after influenza. Ever afterwards she was troubled with all the symptoms of emphysema. For about nine months she had been subject to another complication, pain in the lower part of the abdomen, chiefly towards the left iliac fossa. Two months before admission Dr. Blamey's attention was turned to an abdominal swelling of considerable size lying somewhat to the left of the middle line. At that time symptoms of peritonitis came on periodically, subsiding under rest and opium. The tumour became rather smaller.

The patient was somewhat thin, her cough troubled her, and emphysema was marked at both apices. A spherical swelling occupied the middle line of the abdomen from the umbilicus to the pubes. It bulged perhaps a little more to the left than to the right. At first it seemed solid although elastic, but fluctuation could be felt after the patient had rested for a few days. The swelling could apparently be moved laterally, but returned into its place when let go.

On vaginal exploration the cervix was found fairly long, lying backwards. The sound passed two inches, somewhat forwards. The uterus seemed to slide laterally behind the tumour.

The tongue was clean and moist, the appetite much impaired since the recent attacks of abdominal pain, and the bowels were sluggish. During the first week spent in the hospital about 40 ounces of urine were passed daily. It was always clear, and never contained albumen, but varied considerably in colour and in specific gravity (1009 to 1022) daily. During the same period the temperature ranged from $97 \cdot 6^{\circ}$ to $98.8^{\circ}$; the pulse was 96 , regular, small in volume, and hard.

Diagnosis was very uncertain. Ovarian cysts are so frequent, and vary so much in character, that $I$ was inclined to take this swelling for a tumour of that familiar type. At the same time I bore in mind Dr. Blamey's history, and suspected that the swelling might be a circumscribed collection of peritoneal effusion. The latter 
explanation seemed to be verified at the operation; but after due deliberation and consideration of notes, which I took directly after I closed the abdomen, I came to the conclusion that adhesive peritonitis had evidently taken place around the limits of the tumour, but that the tumour itself was not an encysted dropsy of the peritoneum.

On October 6th I operated, assisted by $\mathrm{Mr}$. Corrie Keep. On dividing the aponeurotic layer of the wound, a thick, tough, yellow membrane was exposed. I incised it carefully; about a pint of a dirty greenish-brown fluid escaped, with shreds resembling products of inflammatory effusion. I washed out the cavity thus laid open with iodine water; then I opened it more freely, and found that close to the umbilical level of its wall the yellow membrane passed backwards, where it formed a well-defined septum between its cavity below and adherent intestine and omentum above. Beyond the region of adhesion the intestines seemed healthy. The attacks of peritonitis could now be accounted for.

I traced the yellow membrane downwards, and came upon a second and smaller cyst or loculus immediately below the larger cavity. The yellow membrane bounding the latter passed directly backwards over the top of the lower cyst. I have now no doubt that the same membrane formed the back of the upper cavity. I naturally suspected, from its position, that the lower cyst might be the bladder, as inferiorly it lay in connective tissue, and was closely applied to the parietes in front. A sound was passed and held in the bladder. When that instrument was pushed as high as possible I found that it was behind the cyst. I tapped the latter, and about half a pint of dirty greenish-brown fluid escaped. On opening this lower cystic cavity freely I could feel the tip of the sound behind it. The walls could not safely have been separated from the bladder. When mopped with absorbent gauze the interior of the cyst remained dry; no fluid resembling urine ever escaped afterwards from either the upper or lower cavity. I packed the lower cavity with 
iodoform gauze, took pains to close the general peritoneal cavity near the umbilicus, so that it could not be infected, and lastly packed the greater cavity. Its inner wall posteriorly felt rough all over, and was fairly uniform; it was, in short, something more than mere effusion covering intestine, and was continuous with the reflections of the yellow membrane above described. I cut away the contiguous boundaries of the two cavities in order to facilitate packing and drainage. Two stout red rubber drainage-tubes were inserted into the lower angle of the wound.

On the third day the iodoform gauze was removed; it was blood-stained, as might be expected. Nothing but serum, ultimately clear, flowed from the tubes; they were therefore removed. For a fortnight the cavity was washed out with iodine water. During convalescence there was neither fever nor rise of pulse, the urine exhibited no morbid conditions, and there was no discharge of any kind of fluid from the cavity. No symptoms of peritonitis were observed, nor was there any trouble about flatus.

On October 27th the patient was discharged from the hospital. The uterus was fairly moveable, the fornices free, and there was no dysuria.

On November 11th I saw her again. The cavity was reduced to a small sinus; she had syringed it daily with a weak solution of carbolic acid. There was resonance all over and around the cicatrix, under which a hard area could be felt, probably the shrunken cyst wall. The uterus remained fairly though not freely moveable. Douglas's pouch and the lateral fornices were quite free.

March 6th.-Dr. Blamey wrote: "Mrs. S- is now quite well. The little wound was somewhat stubborn, but has now quite healed up."

A small piece of the wall of the larger cyst cavity was preserved, and Mr. Corrie Keep made sections of it. We fancied that there was tissue like muscular fibre in its substance. I therefore took a section to Mr. Shattock, who kindly made the following report: 
" Royal College of Surgeons;

"Jan. 26th, 1898.

"I have very carefully studied the section of (?) urachal cyst.

"Firstly, there is no histological sign of tuberculosis.

"On the convex under aspect the section shows a fairly broad zone of close fibrous tissue, but in the rest of its extent the preparation consists mainly of unstriped musclefibre arranged in bundles (Pl. VIII, fig. 1). I am quite satisfied that this is so, as one can see the cross-sections of the muscle-cells with small circular (in sectional area) nucleus lying in the cell body, which latter can, moreover, be traced for a considerable distance, by altering the focus, beyond the termination of the nucleus. In the longitudinal sections of the muscle-bundles here and there isolated cells of the typical elongated, tapering form, with central staff-shaped nucleus, are encountered.

"There is no epithelial lining and nothing like a mucosal corium, apparently from artificial damage, since the actual inner surface is constituted by frayed-out vascular tissue, and is not even graulating.

"I think, therefore, that the diagnosis of urachal cyst is securely established.

"S. G. Sha'tтock."

I will defer all comment on this case until after consideration of the somewhat similar experiences of other operators. Before turning to their reports, I think it advisable to dwell a little on the normal urachus itself and on the experience of pathologists, which at least proves that minute cystic dilatations of its canal must be frequent. After considering the records of suspected cases where an operation was performed, I will in conclusion turn the Society's attention to a remarkable type of abdominal cyst, originally described by Mr. Lawson Tait, who ascribes it theoretically to the allantois. His cases have been repeatedly quoted, and much that he himself rates only as theory has been accepted as fact. Hence 
they are important enough to deserve full consideration, and obscure enough to demand the most critical scrutiny.

\section{The Normal Urachus.}

The homologies of the urachus are so well determined that I need say nothing about its comparative anatomy.

We are all familiar with this fibro-muscular cord which runs between the summit of the bladder and the umbilicus. Posteriorly its attachment to the bladder corresponds to the reflection of the parietal peritoneum on to that organ. Hence it marks the limits of the portion of the bladder invested by peritoneum, as immediately in front of the urachus and from thence forwards and downwards the bladder has no peritoneal covering, but is separated from the body of the pubes and the abdominal wall by connective tissue sufficiently loose to allow it to move as it fills and empties itself of its contents.

This connective tissue lies in front of the urachus itself, and usually is less abundant as the cord passes in front of the peritoneum upwards to the umbilicus; yet I have found the urachus lying behind very loose subserous connective tissue all along its track. In cases of abdomino-pelvic tumour this tissue is often'very abundant, while the urachus undergoes hypertrophy.

Thus the cellular surroundings of the urachus must allow of the free expansion of any cyst, or any collection of fluid without a true wall, in their neighbourhood. Of course this applies to a true urachal cyst, but it does not follow that every cyst in this region is urachal. The connective tissue might suppurate from injury or anterior parametritis, and an abscess cavity might remain and assume a cyst-like character. Hydatids, too, must not be overlooked.

When chronic peritonitis exists, this connective tissue becomes soldered to the transversalis fascia and to thickened peritoneum, greatly confusing relations, especially if 
an ovariau cyst with thick laminated walls happen to be adherent to the peritoneum. The urachus, thickened and otherwise altered, may be a stumbling-block instead of a guide. I have myself divided it, laying bare a patulous portion of its canal, in one of these complicated cases, and can understand that the discovery of a tubular structure on the front of an inflamed cyst might puzzle an unwary operator.

\section{The Canal of the Urachus.}

This leads to the question how far the canal of the urachus may be pervious in the adult. I believe that it is impossible to draw the line between the normal and the abnormal in this question. The origin of the urachus may look very like a diverticulum, as in one female subject in the Normal Anatomy Series of Dissections by Mr. Pearson at the Museum of the Royal College of Surgeons. In this case a small digital protrusion may be seen running for half an inch from the top of the bladder till it abruptly joins its smaller and more normal portion. In another subject in the same series there is a distinct indication of a diverticulum, whilst in another not the faintest trace of such a protrusion can be detected. In abdominal operations I have noted similar variations. Most probably more or less patency is the rule. Luschka (Pl. VIII, fig. 2) and Wutz's researches should be followed up; the latter observer, who examined seventy-four subjects, found that the epithelial part of the urachus steadily grows up to the twenty-fifth year, its canal becoming wider. Its growth is, however, less rapid than that of the tissues of the abdominal walls, so that it ceases further and further from the umbilicus as the subject grows older. Wutz distinguished a transverse valvular fold to the vesical orifice of the urachus which prevents the passage of urine into the urachal canal (Fig. 5). This seems to 
explain why urachal fistula has been found to develop when there is obstruction to the passage of urine out of the urethra, and why urinary fistula sometimes develops after incision and drainage of a urachal cyst which at the operation seemed unconnected with the bladder. Wutz's valve is, in fact, liable to be forced open by the pressure of urine retained in the bladder. The canal of the urachus is lined with stratified epithelium below. Wutz distinguished three layers; higher up the layers are reduced to two, and near the upper extremity of the tube to one. He found that the cells individually vary in shape; some are flat, some large and oval with big nuclei, some bear one or more long processes. Much has been made of these statements, as will be seen; but before we feel certain about the significance of cells in the walls of cystic tumours in the abdominal parietes it would be better for us to investigate Wutz's researches or to entrust such an investigation to a competent histologist. Under the epithelium of the canal and its subepithelial connective tissue there is a layer of plain muscle-cells.

The muscular sheath of the tube, the middle true ligament of the bladder, becomes more and more mixed with white fibrous tissue the nearer the urachus approaches the umbilicus, so that at length it is reduced to a tendon (Pl. VIII, fig. 2). Mr. Keep has prepared for me the sections, which I now exhibit (Pl. IX, figs. 3 and 4), of the urachus of a woman aged 45. Plain muscle-cells are to be seen in abundance, arranged with much regularity in bundles which nearly all seem to run vertically. In the child the urachus remains muscular half the way up ; in the adult the tendon begins lower down. It is clear that a pervious urachus is very frequent, if not the rule, in the human body. 


\section{Urachal Fistula.}

Of all pathological conditions affecting the urachus, it is urachal fistula that is best known to the surgeon. It allows of the escape of urine through the umbilical orifice, and even calculi may come away through it. In the most aggravated form the urachus is represented by a long and wide process of the bladder opening at the umbilicus. Many cases have been published. A patulous condition of the lower part of the urachus may give trouble, though the canal remain closed near the umbilicus.

In the early days of the Pathological Society of London, $\mathrm{Mr}$. Stanley reportied a case which seems to come under this class. There were growths in the bladder, and an abscess in the middle line of the abdomen above the pubes. The abscess was opened just below the umbilicus, which was not patulous, and urine escaped mixed with pus. The patient, a boy aged two, sank from exhaustion a few weeks later; in the interval between the operation and the patient's death no urine was passed naturally, all escaping from the wound. At the post-mortem, the opening in the abdominal walls was found to lead into an abscess between the recti and the peritoneum. At the lowest point of this abscess the end of the urachus was seen projecting from the fundus of the bladder. The tube of the urachus was free to the bladder, but no passage çould be clearly traced from the urachus through the wall of the bladder into its cavity. I am here quoting from the original report written for Mr. Stanley by Dr. W. S. Kirkes, and preserved in the MS. "Report of cases in St. Bartholomew's Hospital,"' vol. v, p. 485 . Dr. Morley Fletcher, who kindly found out for me the above report, after diligent search, has also turned my attention to specimen No. 2419 in the museum of St. Bartholomew's Hospital, where there is a sarcoma of the bladder, and an abscess cavity above it, extending to the umbilicus, "but no communication can be traced between the two (bladder 
and urachus), although the urine continued to escape by the abscess up to the time of the child's death. The small papilla close to the vesical termination of the abscess is all that appears of the urachus." This specimen is most probably the same as Mr. Stanley's above described; it was reported on independently by Sir William Savory, and exhibited before the Abernethian Society in 1851, five months after Mr. Stanley showed it at the Pathological Society. Stanley in his MS. report believed that the sarcoma in the bladder caused obstruction, one consequence being that the urachus reopened. He further considered that the canal of the urachus ruptured, and the extravasated urine set up an abscess ; but this theory is doubtful. More probably Wutz's valve was forced when the bladder was full of urine, as "the tube of the urachus was free to the bladder," but it could not be detected after death; indeed, its existence was not known in 1851, and it is not always distinguished with ease. ${ }^{1}$

I need not dwell on the commoner form of urachal fistula which opens at the umbilicus. Much has been written on this condition (Paget of Leicester, Jordan Lloyd, \&c.). It must not be confounded with a diverticulum from other parts of the bladder. Boyer believes that in obstruction to the passage of urine through the urethra, a hernial protrusion of the mucous membrane of the bladder may develop and push up to the umbilicus. This theory seems doubtful when we bear in mind Luschka and Wutz's researches, which show the frequency of an open urachal canal. Mr. Henry Morris has published some instructive information on urachal fistula.

1 Since this memoir was prepared, Mr. John Morgan hus referred to the specimen, No. 2419, in his Lettsomian Lecture ('Lancet,' 1898, vol. i, p. 710). 


\section{Cystic Dilatations of the Urachus.}

Much more pertinent to the present subject are the minute dilatations of the urachal canal noted by several observers. The indefatigable $\mathrm{Wutz}$, whose care in investigating the foundations of the subject makes his opinions on more important questions presently to be discussed all the more reliable, succeeded in detecting exactly two dozen examples of cystic dilatation of the canal in his seventy-four post-mortem examinations to which I have already referred. They all lay in the lower third of the urachus, and varied in size from microscopic dimensions to the bulk of a bean (Fig. 5). They were lined by parement epithelium, as a

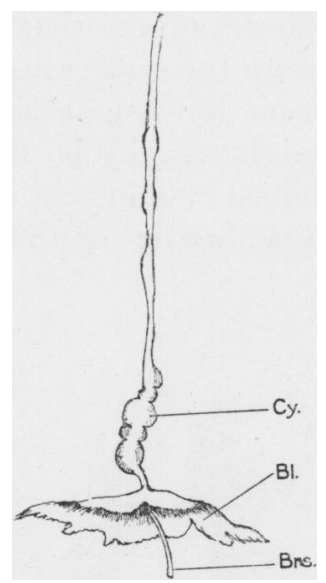

FIG. 5.-Cystic dilatations on the urachus, from a woman aged 66, who died of strangulated hernia (after Wutz). The canal here represented measured 3 inches. Immediately above the bladder (B1.) a row of five small cystic dilatations (Cy.) bulge from the urachal canal. The largest was as big as a pea, their cavities communicated, and a fine bristle (Brs.) could be passed from the bladder through the cavity of the cysts, and for some way up the canal above them; the vesical orifice is guarded by a mucous fold.

rule stratified, and there was a capsule of plain muscle cells on the outer surface, a very important fact in relation to the microscopical examination of sections of the wall of a cyst suspected to be urachal (see Pl. VIII, fig. 1). Wutz 
found inflammation and suppuration of these minute cysts in a case of fatal bladder disease in an old man and in a case of fatal peritonitis from perforation of the vermiform appendix in a youth aged twenty. This fact, that an abscess may develop in a small urachal cyst, must be borne well in mind. Supposing that it grows larger as an abscess, or supposing that a large urachal cyst suppurates, the epithelium would be destroyed, and probably the muscular capsule so altered as to escape detection. Hence an abscess in the middle line of the abdominal wall below the navel may well arise from inside the urachal canal, and the absence of the essential histological elements of urachal tissue does not always prove that a cyst in this region cannot have developed from the urachus. I may further suggest that a urachal abscess might burst and open up the subserous connective tissue. If it remained quiescent for some time, a clear fluid replacing the pus, it might readily be taken for a cyst of the urachus, and indeed would be a cyst of urachal origin; but no characteristic epithelium or muscular

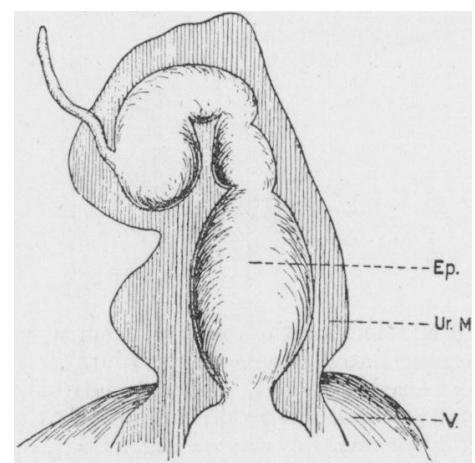

Fig. 6.-Cyst of urachus (Wutz, after Walter). Ep. Epithelial and subepithelial tissue of urachus irregularly dilated. Ur. M. Muscular coat of urachus dissected backwards. V. Bladder.

fibres would be found in its walls. The largest cystic dilatation in which Wutz believes is that described by Walter (Fig. 6). 


\section{Cystic Tumours of the Urachus.}

As it is evident from the above researches that cystic dilatations of the urachus are by no means rare, it is reasonable to believe that they may develop into tumours capable of giving rise to marked clinical symptoms. Hence certain cystic tumours discovered between the abdominal parietes and the parietal peritoneum in the middle line below the umbilicus have been reckoned as urachal on very fair grounds. Yet, for various reasons, perfect evidence seems unobtainable in any one case. Wutz's researches were undertaken under every advantage for precise histological research ; in operative practice these advantages are absent.

I will dwell a little on some of the most probable cases of " urachal cyst."

An instructive case is reported by Mr. George Morgan, of Brighton. A boy aged five years was admitted into the Children's Hospital with vomiting and diarrhœa, indicating, it was believed, peritonitis secondary to severe enteritis. Abdominal section was performed, and a cyst was found communicating with the bladder, so that urine escaped when its wall was opened. After careful dissection around the cyst the peritoneal cavity was exposed and flushed. 'The patient was too ill to allow of close examination of the parts, nor did Mr. Morgan attempt to dissect away the cyst wall, "but it was certain that the cyst was in the middle line running up to the umbilicus and communicating with the bladder." The cyst and bladder were washed out with boric solution; the wound in the cyst was closed with a double row of silk sutures, the stitches not penetrating to the mucous membrane. The abdominal wound suppurated, and pus and urine escaped for some days during convalescence, but the patient was well at the end of a month.

I place this case first, not only because it is relatively new (1896), but also because it seems transitional between 
urachal fistula and urachal cyst. A typical fistula opens at the umbilicus and bladder. In Mr. Stanley's case the urachus or its suppurating cystic dilatation communicated with the bladder only. In Mr. Morgan's case we see a step further, for a definite cyst opened into the bladder. Let it be noted that here, as seems frequent in cases of patulous urachus, suppuration took place.

We now come to the typical cyst, which is cut off both from the umbilicus and the bladder. As its cavity is kept free from septic influences, suppuration seems rare.

Lawson Tait and Teichelmann's case might well be an instance of a genuine cystic tumour of the urachus. The patient was a married woman aged twenty-eight, who had miscarried twice, several years before the illness which brought her under observation. An attack of fever and vomiting occurred, a hard painful swelling developing between the umbilicus and pubes, somewhat to the left; at first there was dysuria. The general disturbance abated. The tumour filled the pelvis, and extended above the pubes in the middle line and to the left.

At the operation, three months after the attack of feverishness, the "tissues in the middle line were found thickened and cartilaginous in density." The tumour was a large cyst dipping into the pelvic cavity, which, indeed, it seemed to fill, but not adherent to its contents. "It was attached," the authors state, "by a short sessile (sic) pedicle, of more than two fingers' diameter, to the abdominal wall, somewhat to the left of the middle line and about two fingers' width above the pubes." 'The cyst was easily enucleated, the cavity drained, and the margins stitched to the abdominal wall. The peritoneal cavity was drained separately. The patient was discharged from hospital cured at the end of three weeks. This cyst seems to have been really outside the peritoneum, and from its position in the abdominal wall was most likely of urachal origin. Microscopical evidence seems wanting. 
The next case is reported by Dr. Edward Ill, of Newark, New Jersey, in a valuable monograph on 'Tumours of the Abdominal Wall' which appeared six years ago. I will reproduce the author's own words. "The patient had noticed a tumour of small size for about ten years, when it suddenly took on rapid growth during a pregnancy, and contained five litres of fluid by the third month. Incision and drainage cured her. She miscarried two weeks after the operation. This miscarrying after the operation is by no means rare (Tait and Roser). This very slow growth was noticed in one of Hoffmann's cases."

Here it is probable that the tumour arose from the urachus. Unfortunately Dr. Ill makes no note of the appearance of the wall of the cystic cavity when it was divided at the operation, nor does he say that he made out the peritoneal relations at the upper limit of the cyst wall, as I think could be done in my case ; still less could he approach so near to certainty as Dr. Douglas of Nashville, who in his case succeeded in dissecting away the cyst wall from the parietal peritoneum which lay behind it. Nor does Dr. Ill seem to have read Wutz's criticisms on Hoffmann's and Roser's so-called cysts of the urachus, presently to be considered, and he further appears to take for granted what Mr. Lawson Tait himself, as will be seen, admits to be theoretical.

A case of considerable interest was reported last October by Dr. R. Douglas, of Nashville, Tennessee. The patient was a sterile woman aged thirty-six, married eleven years. "About eighteen months ago she observed a swelling in the lower part of the abdomen, rather prominent on the right side. The enlargement was soft and painless. It grew slowly and did not materially show until the last four months, within which time its growth has been rapid, chiefly to the right side." The abdomen was asymmetrically distended to about the size reached at the serenth month of pregnancy, and chiefly to the right. It was soft, fluctuating, compressible, and fixed. The uterus was small, retroflexed, and low in the pelvis; the 
fluctuating swelling encroached on the anterior vaginal fornix. Diagnosis was uncertain.

At the operation, on cutting through the linea alba and transversalis fascia, Dr. Douglas exposed a " red, congested cyst wall," which he tapped, drawing off twentyfive pints of clear pale green fluid containing a few. flocculi. As the sac collapsed it became evident that the peritoneal cavity had not been opened. 'The operator now felt sure that he had to do with a cyst of the urachus. It was easily enucleated, with but little hæmorrhage; the viscera could be felt through the parietal peritoneum exposed when the cyst was removed. The cyst wall dipped into the true pelvis in front of the uterus, which it thus displaced. It had no special attachment even to the bladder. A wide area of parietal peritoneum detached from the back of the cyst was simply left loose, the operator hoping that intra-abdominal pressure would bring it in apposition with the wall. Unfortunately it hung loose, and seems to have been the cause of the patient's death within forty-eight hours. The fluid was inadvertently thrown away. 'The cyst wall was thin and made up of "fibrous material showing no evidence of muscular structure."

This case seems as nearly genuine as the evidence available under the circumstances can make it. The cyst lay exactly in the site of the urachus, and was certainly not a diverticulum of the bladder. That it was extra-peritoneal there could be no doubt, for the serous membrane detached from the back of the tumour was found after death to be continuous with the rest of the peritoneum. Although no definite statement is made about the postmortem appearances of the pelvic viscera, the author evidently implies that they were separate from the cyst, which could hardly, then, have arisen from the ovary or parovarium, burrowing forwards; microscopic evidence was negative rather than contradictory. No plain musclecells were detected, but the cyst wall had been greatly stretched for some time and apparently inflamed as well, 
so that muscular tissue might have once existed, and undergone atrophy.

Granting that there can be cystic tumours of the urachus, it is not difficult to understand that they may incline very much more to one side of the middle line than to the other, for even the minute dilatations of the urachus already described are sometimes asymmetrical from the first.

Evidence in the Author's Case.

I will now explain how far the evidence was in favour of the theory that in my own case the tumour was a true cyst of the urachus.

The upper cyst, or loculus, occupied the greater part of the site of the urachus (Fig. 7). As far as could

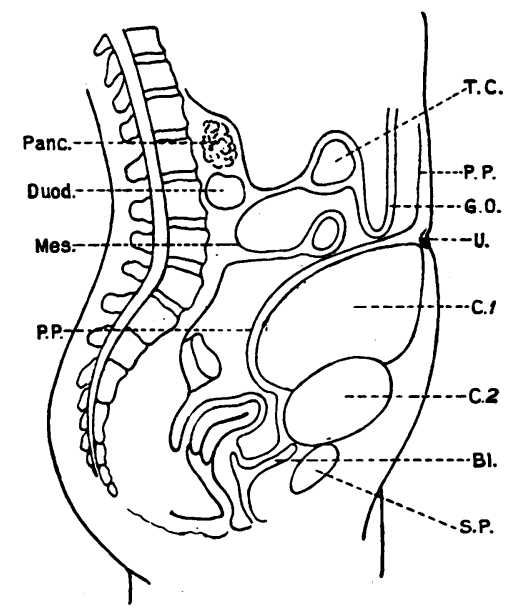

Fra. 7.-Diagram illustrating relation of the urachal cyst to the peritoneum (nuthor's case). U. Umbilicus. C.1. Main cyst. C.2. Smaller cyst or loculus. Bl. Bladder, empty; a sound could raise fundus till it lay behind C.2. P.P. Parietal peritoneum pushed backwards by the cyst below the umbilicus. T.C., G.O., Mes. Transverse colon, great omentum, and mesentery, with small intestine displaced upwards by the larger cyst. Panc., Duod. Pancreas and duodenum. S.P. Symphysis pulis. 
safely be ascertained at an operation, the appearances at its uppermost limits, already described, suggested that a true cyst wall and not an inflammatory peritoneal adhesion cut off the viscera and the peritoneal cavity from the parietes below the umbilicus. The posterior part of the cavity seemed to be lined by a definite regular wall, continuous with that in front, and could hardly have been mere organised peritoneal effusion concealing intestine.

The existence, position, and appearance of the lower cyst, or loculus, greatly added to the probability that the whole tumour was urachal. It had a very definite wall bulging prominently upwards from the connective tissue in front of the bladder into the cavity of the larger cyst. When I exposed it I thought that it might be a small encysted dropsy enclosed in the fold wade by the parietal peritoneum passing on to the bladder, but it is difficult for fluid to collect in that fold, and I have never seen nor ever heard of an authentic case of a cyst thus developed. An encysted dropsy so perfectly bilocular is highly improbable. The prominent well-developed septum, or upper part of the lower cyst, was very unlike an inflammatory product, but closely resembled the septa seen in entirely neoplastic cystomata and in cysts due to congenital malformations. In short, it seems reasonable to believe that the two cysts were developed from the beadlike dilatations detected by Luschka and Wutz (Fig. 5) in the urachus in many post-mortem examinations.

The strongest evidence, however, that the cyst arose from the urachus was afforded by microscopical examination of sections of the cyst wall. $\mathrm{Mr}$. Shattock found that the wall was largely made up of plain muscular fibre (Pl. VIII, fig. 1) ; and Luschka (Pl. VIII, fig. 2) and Wutz have both proved that there is a muscular coat to the urachus, very conspicuous in the sections of normal urachus exhibited this evening ( $\mathrm{Pl}$. IX, figs. 3 and 4). Wutz further discovered a special muscular capsule to the minute cystic dilatations already described. 
The anatomical relations were made at least sufficiently clear at the operation to prove that the cyst wall could not have been derived from the broad ligament.

The loose flocculi which floated about in the cyst were carefully examined under the microscope by Mr. Keep, who could not find any hooklets or other elements detected in hydatid cysts. The presence of the well-defined loculus, or second cyst, showed that the tumour could hardly have been an old abscess cavity due to anterior parametritis or to direct injury of the parietes in the middle line.

Other cases similar to those just described have been related, but I need not multiply examples. Dr. D. Newman's case (" Cyst of Urachus," 'Glasgow Med. Journal,' vol. xliv, 1896, p. 20) was like G. Morgan's, the bladder opening into a urachus not pervious at the umbilicus, so that it became greatly dilated. When the patient was thirty-nine he underwent operation. The cyst, or dilated urachus, was drained, urine escaping for about a month, then it closed completely. Rotter ("Urachus-cyste mit Carcinom der Blase," 'Deutsche med. Wochenschrift,' Jan. 20th, 1898, Supplement, p. 10) dissected out a large urachal cyst, with the parietal peritoneum adhering posteriorly, and then found that its walls below were continued into the vesical walls. At the point of junction was a small villous cancer of the vesical mucous membrane already diagnosed by the cystosoope. He excised the cancer with the contiguous part of the bladder and the whole urachal cyst. The wound in the bladder and the abdominal incision were carefully closed, and the patient recovered speedily. The relations of the cyst, so evident in this case, seem to leave no doubt as to its origin. ${ }^{1}$

Sutton and Aveling's extra-peritoneal tumour, described in the second volume of the 'British Gynæcological Journal' (p. 187), was a myo-sarcoma of the muscular sheath, not a cyst developed from the urachal canal.

1 See Addendum, p. 335. 
Tait's so-called Allantoic Cysts.

Over ten years since, Mr. Lawson Tait published a report of high importance ou a series of cases where a capacious cystic cavity was found occupying the middle and lower part of the abdomen and the whole of the pelvis. He maintained that it was extra-peritoneal, and represented an extreme form of urachal cyst. He ventured further on a very bold and ingenious theory, though it must not be forgotten that he has never professed that it was more than a theory. "I think I have a satisfactory explanation to give of them" is the most definite statement he makes concerning his cysts. Dr. Byron Robinson, the chief upholder of the theory, is almost as cautious. I cannot find any corroborating evidence since the original reports of Mr. Tait's cases were published by the operator and by Dr. Robinson.

The theory is not very difficult to understand, and as Dr. Robinson endeavoured to make it clear by a diagram, I have prepared a sketch which perhaps illustrates the relations of cyst and peritoneum yet more completely (Fig. 8). Mr. Lawson Tait believes that the first change is arrested development early in embryonic life, when the allantois is growing out of the peritoneal cavity. The allantois ceases to be a part of that cavity, and does not contract into the vesicle into which it normally dwindles. Here it is noted that the umbilicus always seems to open straight into these large abdomino-pelvic cysts. The peritoneum can develop normally in its upper part, but it is arrested inferiorly by the persistent allantois. Hence according to this doctrine the upper viscera receive their normal serous investment by pushing forwards the peritoneum in front of them.

The pelvic viscera, however, which lie entirely below the peritoneum push forwards the posterior and under part of the allantois and thus make for themselves serous folds out of the allantois itself. As Mr. Tait says, the 
cyst which goes down into the pelvis is, according to his theory, developed from the allantois, and acts as peritoneum for the pelvic viscera. No other peritoneum, he insists, ever entered the pelvis in his cases.

Twelve cases of these large cysts have been described by Mr. Tait, and Dr. Robinson adds some more observed in

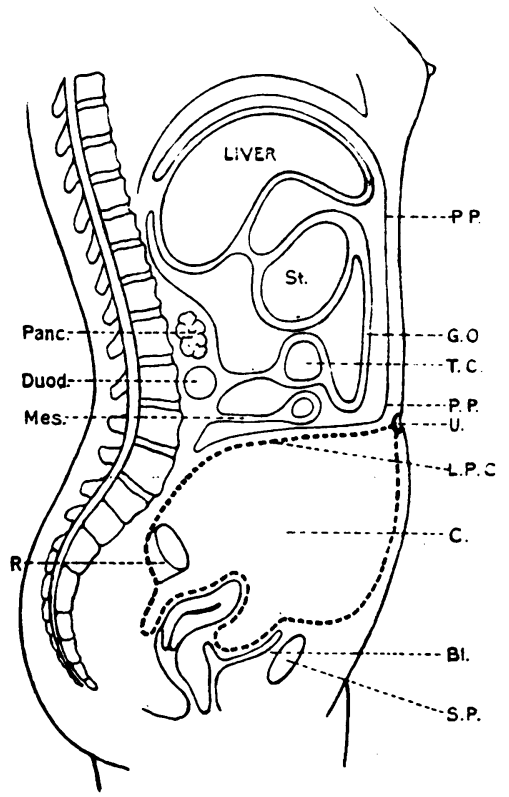

FIg. 8.-Diagram illustrating Lawson Tait's and Byron Robinson's theory on relations of large "allantoic cysts" to the peritoneum. C. The "allantoic cyst" dipping into the pelvis. Its wall is indicated by a dotted line, and it is seen reflected, according to the theory, over the pelvic viscera, after the manner of normal peritoneum. U. Umbilicus. P.P. Parietal peritoneum. L.P.C. Limits of the peritoneum and cyst wall, the former not extending, according to the theory, below the level of the umbilicus. T.C., G.O., Mes. Parts displaced as in Fig. 7. Bl. Bladder. R. Rectum. S.P. Symphysis pubis.

Mr. Tait's practice. The cases themselves have been repeatedly quoted, and cannot be discussed here at any length. But of the original twelve recorded by Mr. Tait himself, three died from the operation, and a fourth died 
just a month afterwards from miscarriage, being pregnant when operated upon. Unfortunately there was no necropsy on any of the four. These cases were no doubt very ill, and the justifiability of an exploratory incision need not be disputed. At the same time all seem to show evidence of much more pathological mischief than could be accounted for by a purely teratological condition, which does not imply inflamed tissues or acute disease and which let the patients live in comfort to adult life. ${ }^{1}$

The same can be said of the eight other cases which recovered. The common features were the existence of a spacious cyst-like cavity in the abdomen and pelvis, and the alleged absence of peritoneum between the transversalis fascia and the cyst wall. The operator noted in several cases how the peritoneum left the abdominal wall about or above the level of the umbilicus, passing back over the top of the cyst, whilst the cyst wall lined the pelvic viscera and bladder as peritoneum (Fig. 8 explains this alleged condition). He declares how, in one case, the cyst wall seemed reflected over the ovaries and tubes, whilst the intestines lay in a pouch of peritoneum on the top of the back part of the cyst immediately above the level of the sacral promontory, ${ }^{2}$ just as they are normally seen much lower down in Douglas's pouch. The writer signifies, no doubt, the small intestines, for if his theory be true the sigmoid flexure and part of the rectum would, after the fashion of the uterus and tubes, push forwards for themselves an allantoic serous investment, so that there would be an allantoic Douglas's pouch in the normal position of that fold, far below the pouch formed by the lowermost limits of the curtailed true peri-

1 I find that Mr. Henry Morris (loc. cit., p. 1067) observes, "It is a remarkable thing, if the theory of the urachal origin of these cysts is correct, that the cysts remained so many years in abeyance, and then suddenly developed to such an enormous size."

2 This pouch would be the posterior inferior extremity of the peritoneal sac indicated under the mesentery (Fig. 8). If full of intestine it would press against the promontory of the sacrum. 
toneum. Whilst this latter, or false Douglas's pouch, is described as above related in one case, the ninth, Mr. Tait states that in the tenth the cyst wall was reflected over the pelvic organs, the intestines behind the posterior cyst wall being attached to it by connective tissue, as where there is normally no peritoneum. It is implied that this connective tissue is not an inflammatory product, not old adhesion in fact. The observation is very interesting, but if correct would represent a condition not explained by the allantoic theory. Where was the lower limit of the true peritoneum in this case? How came the intestines to be devoid of peritoneum? or if they be allowed their mesentery and serous coat, how came they to lie outside both the parietal peritoneum above and the allantoic cyst wall below?

Most of these cysts contained great quantities of fluid, one as much as thirty pints. Broken-down lymph and amongst other things masses of fat like omentum were found in the fluid. Byron Robinson examined similar cases in Mr. Tait's practice and found flaky flocculent lymph shreds and gelatinous masses, or even thick pus, in the cavities of these great cysts. As for the cyst wall, it was often as " thick as sole leather," very easily torn, and gelatinous, unlike peritoneum, whether it lay against the transversalis fascia replacing (as was believed) the parietal peritoneum, or lined the pelvic viscera in the manner already described. These appearances will be further considered.

Undoubtedly the large cysts described by Mr. Lawson Tait represent a remarkable condition, very puzzling to the operator. Mr. Tait deserves great credit for describing them, and Dr. Byron Robinson must be thanked for giving a clear demonstration of the "allantoic cyst" theory. But the evidence that these cysts are urachal remains defective. I will now consider some reasonable objections.

1. Tait and Robinson definitely state that the allantoic origin of these cysts has not been verified by post-mortem 
dissection in any of their cases. Bland Sutton does not distinctly accept the theory.

Mr. Tait's words are, "It remains quite uncertain what the exact nature of the tumours really was, though I think I have a satisfactory explanation to give of them."

Dr. Byron Robinson declares that " it must be admitted that we have so far no conclusive scientific post-mortem of cases in which the urachal cyst completely fills the whole pelvis, and until such autopsy is produced with frozen section, we must wait for light."

Mr. Bland Sutton writes, "Lawson Tait has published details of allantoic (urachus) cysts that have obtained large dimensions. .... At present so little is known about the cysts that it is impossible to decide as to the best method of dealing with them." This distinguished pathologist has made some instructive observations on urachal cysts and their comparative anatomy; but the words just quoted were written several years after his own report of microscopic appearances seen in Mr. Tait's cases; this report will presently be discussed.

2. Wutz, who wrote earlier than the above-named authorities, demonstrates grave errors in the post-mortem reports of cases with similar symptoms described as "cysts of the urachus," and in the clinical records of other cases, so described, which recovered.

Thus out of Hoffmann's three cases of supposed " cysts of the urachus" repeatedly quoted, in one the urachus was simply pervious throughout in a man aged twentyeight, and in the second the cyst lay in the upper part of the abdomen and was most probably hepatic. There remains the famous case often referred to in the allusion that " cysts of the urachus have been known to contain fifty litres of fluid." Wutz fifteen years ago wrote a very depreciatory report of this case. ${ }^{1}$ The patient was a man aged

1 Freer (as well as others) has clearly overlooked this report. He relates Hoffmann's case (loc. cit., p. 111), correctly noting that the fifty litres were found in the cyst after death, but accepts Hoffmann's interpretation unreservedly. 
twenty-six; the symptoms reasonably led to the diagnosis of chronic peritonitis. He died after repeated tappings, and the famous fifty litres were discovered not at an operation but at the necropsy. The value of the original post-mortem report as an accurate guide is indicated by Wutz when he comes to a passage in that document which states that the wall of the cavity was reflected "over the excavatio recto uterina." Here he adds his own note in parentheses " (Man!)." He further, having examined the specimen in a museum, finds ng evidence that the cyst wall was extra-peritoneal at any point. It may here be noted that the wall was originally reported as lining the under surface of the liver; in Pratt's case, to which I must again refer, the same condition was detected. Above all, Wutz found that the urachus was quite separate from the cyst, and only contiguous to the outer part of its wall near the umbilicus. He considers, in fact, that Hoffmann's famous " urachus cyst" was simply a case of chronic hæmorrhagic peritonitis. Let writers beware of second-hand information, especially when in the original there is talk about the recto-uterine fold in a male subject.

Wutz's comment on Heinecke's case is especially important, as according to the original it resembled a "Tait's cyst." On tapping "pavement epithelium in a state of fatty degeneration" was obtained, and on the strength of that discovery "cyst of the urachus" was diagnosed. Hence the operator was prejudiced. On abdominal section no peritoneum was found, and the posterior wall of the cyst was clearly a very thin membrane covering coils of gut. At the necropsy the wall of the cyst was found lining the pelvic viscera, just as in Tait's cases; it likewise lined the under surface of the liver, as in Pratt's and Hoffmann's cases. The cyst was seen to be an encapsuled peritoneal exudation.

Wutz criticises the report of Roser's case, repeatedly quoted as an instance of urachal cyst. A cyst communicated laterally with the bladder; it was incised, and after 
a time a urinary fistula developed. Wutz remarks that the cyst might have been ovarian, or an old peritoneal abscess communicating with the bladder or a vesical diverticulum. The patient was apparently lost sight of, and nothing could be verified.

Lastly, Wolff's case is also very uncertain. A tense cyst lay on the left side of the hypogastrium in a woman aged thirty-one. It was found at the operation entirely in front of the peritoneum, and was enucleated whole, but its base apparently lay deep in the left iliac fossa. There was no pedicle. Plain muscle cells were found in its outer wall. From the situation of its deeper part Wutz strongly suspects that it was a parovarian cyst which had burrowed in front of the peritoneum. The case recalls another related by $\mathrm{Mr}$. Knowsley Thornton. He operated in 1878 for removal of a fluctuating, somewhat flat swelling, which chiefly occupied the left side of the abdomen; the patient was a woman of. thirty-two, almost the same age as in Wolff's case. He came upon what he believed to be a cyst with universal adhesion over its anterior surface, and could not feel certain whether he had cut through the parietal peritoneum or not. After exposing and tapping a cyst full of clear watery fluid, he was able to shell it out from its capsule entire. A cavity was left which passed to the bottom of the pelvis. The uterus could only be felt through a thick membrane, and no other viscera were exposed, but there was yet another large cyst. This was tapped and enucleated; the cavity whence it had been shelled out was separated from that which the first cyst had occupied by a firm membrane. The intestines could be felt through the walls of this cavity. The operator scratched through some tissue at the bottom of the pelvis and reached the left ovary, full of blood and lying in a space cut off by adhesions from the general peritoneal cavity. The patient recovered. The resemblance to Wolff's case is evident ; it is equally clear that an operator prejudiced in favour of urachal cyst might have assigned 
an allantoic origin to the two tumours. They clearly are not examples of Tait's large cysts, whatever the latter may pathologically be, for they were readily enucleated. ${ }^{1}$

3. The evidence of anatomical relations so far as they can be gleaned at an abdominal section is clearly insufficient to settle the allantoic nature of a "cyst" of this class. Thus, amongst other obscure points, it is impossible to prove at an operation that the peritoneum (diseased or healthy) is replaced in the pelvis and lower part of the abdomen by the wall of a supposed " allantoic cyst." It is likewise impossible to prove at an operation that the intestine is attached to the upper and outer limits of the cyst, neither by inflammatory adhesions nor by the inferior reflection of an abnormally short peritoneum, but by connective tissue, presumably subperitoneal as in Mr. Tait's tenth case noted above. Only a very careful dissection or a successful frozen section could settle so important a matter. The question of the reflection of the "allantois" over the lower viscera will be discussed presently.

4. The development of a urinary fistula after drainage of an "allantoic cyst" (Tait, Case 6) seems at first sight to prove that the cyst must be connected developmentally with the bladder; but I have known of urinary fistulæ developing after or during abdominal drainage in cases of chronic, especially tubercular, peritonitis.

In Tait's second case, which was pregnant, a large cyst was found, adherent everywhere. Seven pints of putrid urine were evacuated. As at my operation, an instrument was passed into the bladder, but no communication with the cyst was detected. A urinary

1 As it is practically certain that they were not urachal cysts, I need not enter into Mr. Knowsley Thornton's theory that they developed in the peritoneal subendothelial tissue. I have published my own experience in "Capsules, Real and False, in Ovariotomy," 'Brit. Med. Journ.,' 1896, vol. i, p. 960 . No. 4, fig. 3, in that communicution illustrates a "cyst of ovarian origin burrowing in the lower part of the broad ligament, leaving the meso. salpinx intact." Such a cyst may rise forwards and push up in front of the parietal peritoneum. 
fistula developed three weeks after the operation, and the patient died a week later from miscarriage. There had been violent pelvic pain, sudden abdominal swelling, and retention of urine for twenty-four hours, a mass developing on the left side two days later. Then the operation was performed. This case is very interesting, but does not require an allantoic cyst theory to explain it.

5. It is unscientific, I must admit, to bring forward embryological theories to support or attack some particular interpretation of pathological appearances, but after all we know something about the development of the allantois. The portion retained within the abdominal cavity becomes bladder and urachus. In these great cysts alleged to be allantoic, not only the urachal portion remains open, but that part of the allantois which naturally remains outside the fœtal body becomes, according to Tait's theory, included within the abdomen. How comes it then that the bladder, also a part of the urachus, remains normal, according to clinical and surgical evidence? In cases of quite trifling dilatation of the urachus verified by dissection, the bladder not rarely communicates with the canal of the dilated fotal relic

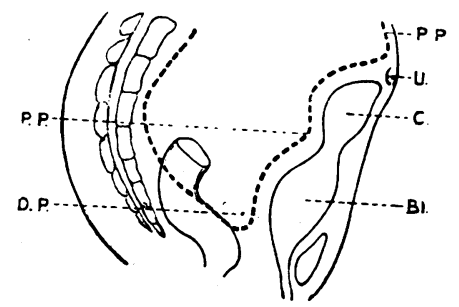

FIG. 9.-Urachal cyst communicating with bladder, in a boy aged 10, showing relations determined after death (after Byron Robinson). C. Urachal cyst. Bl. Bladder. U. Umbilicus. P.P. Parietal peritoneum pushed backwards by the cyst below umbilicus as in Fig. 7. D.P. Douglas's pouch.

(Fig. 9), and the same communication is frequent in fistula of the urachus opening at the umbilicus. If 
Tait's cysts were allantoic, then, judging from what is seen in these less defective conditions, surely there would be ectopia vesicæ or even ectopia of the abdominal viscera. At the very least we must expect something like a vesical fistula. Ectopia of the viscera is essentially due, no doubt, to failure of closure of the visceral folds, but such extreme malformation of the allantois would gravely impede or even prevent that closure. This malformation, in order to meet Mr. Tait's theory, must be established early in fœtal life, when it is conceivable ${ }^{1}$ that the intestines and pelvic viscera could push forwards against an over-developed "allantoic cyst" and become invested by its wall, as they would have normally been invested by peritoneum. These changes, however, are fairly advanced before the abdominal walls have closed in anteriorly, and the abnormal allantois would be in their way. The well-known relations of the allantois to the placenta seem altogether ignored by Tait and Robinson. These relations must suggest to all of us manifest objections to the theory, which it is for those who advance it to explain.

Mr. Bland Sutton has put forward a more logical theory as far as the development of the normally internal portion of the allantois is concerned. "Instead of a portion of the allantois narrowing to form a urachus, the whole of its intra-abdominal portion may dilate and form a large urinary bladder." The words which I have emphasised in this quotation show that his theory is different from Tait's, and would represent a different type of cyst; for according to Tait the external part of the allantois would appear to become included in the abdomen, whilst according to the same observer's surgical experience the urinary bladder always managed to reach its full development, and was leaky in one case only (No. 2). Sutton quotes Mr. Shattock's case, where the abdomen of a four-months' fotus was filled by an

1 Conceivable I admit, though we must not forget that it has never' been proved. 
enormously dilated bladder. In this instance, however, the urethra was imperforate. There is no question of any imperfection of the urethra in Mr. Tait's cases, nor does he base his theory on any such malformation. Urethral obstruction, it is well known, may open up a urachal fistula.

To return to Mr. Tait's views ; Reginald Pratt's case, where the cyst wall appears to have lined the under surface of the liver, is of high surgical interest, but would appear to be a reductio ad absurdum of the allantoic cyst theory. It can be met as such by objection 3, and especially by the argument which I have just advanced about ectopia of the viscera. But Wutz refers to cases, clinically similar, where dissection showed that the "cyst wall" was probably diseased peritoneum, and Dr. Cone of Baltimore's case, as will be shown, throws further light on possible fallacies attending the allantoic pseudoperitoneum theory.

6. Microscopic evidence is unsatisfactory in Tait and Byron Robinson's cases, and is almost bound to be negative (in the sense expressed above in my remarks on the simple type of cyst) in such cases where disease was so advanced, and avowedly complicated in some instances by tubercle. But the evidence was not merely negative, it was sometimes contradictory. In Tait's fourth, seventh, and twelfth cases fragments like omentum were detected inside the cyst. In the twelfth, indeed, Bland Sutton reported one fragment as "omentum," and in the others they very possibly were the same, or else were "masses of congealed fat" such as Cone of Baltimore found in the peritoneal cavity in a case of encysted dropsy of the peritoneum secondary to tubercular disease of the tube and ovary. If so, in either case the "cyst" was simply an encysted peritoneal effusion. In Tait's first case it is noted that "mucoid epithelium" was found on the inner wall. No drawings are given, nor is it stated what is meant by "mucoid" epithelium. Mr. Bland Sutton's evidence in Tait's eleventh case is also inconclusive. 
"By scraping, Mr. Bland Sutton obtained numbers of flattened rounded and pyriform cells, similar to those found in the mucosa of the urinary bladder, though very much smaller. But the patient in this case was a girl of seventeen, with high pulse and temperature. Mr. Tait before the operation suspected tubercular peritonitis, and I cannot help thinking that his diagnosis was correct, and needed not to be replaced by an allantoic cyst theory. The cells obtained by scraping might have been tubercular, identical with the "lymphoid, epithelioid, and polymorphonuclear" cells detected in sections of the serous coat of the uterus in Cone's case of tubercular peritonitis. This recalls to our memory Byron Robinson's researches on a tube and ovary which Lawson Tait had removed from the interior of a so-called allantoic cyst. Dr. Robinson believes, consistently with Tait's theory, that the allantois was reflected over the tube, forming an allantoic instead of a peritoneal broad ligament. This opinion, however, becomes questionable when we compare his description with Cone's account of the serous coat of the uterus in a tubercular case, and find that Robinson admits that "some tubercles with giant cells were visible." Whilst believing that the cyst wall, though of allantoic origin, served as peritoneum to the pelvic viscera, Robinson observes, "However, I must say that this cyst wall does not look much like peritoneum to me, even after making due allowance for pathological changes. In the cases I saw it was as thick as sole leather, friable, brittle, gelatinous, and reflected light when it was torn or cut, just as jelly would." Then he speaks of finding tubercles and giant cells in the mesosalpinx, which he believes to be in these cases an allantoic, not a peritoneal fold.

All this evidence, however, would seem to indicate not only that tubercular disease was present, as is more or less admitted, but further that the "cyst wall" was simply true peritoneum greatly altered by tubercular disease, and covered more or less uniformly with a thick layer of tubercular deposit. 
In Cone's case of tubercular peritonitis, so carefully explored after death, this change produced " an opaque, yellowish-white, felt-like membrane" about a tenth of an inch thick, which was reflected over the pelvic riscera, "forming a complete blanket." In another case in my own practice I found a thick greenish membrane lining Douglas's pouch, and following the reflections of the pelvic peritoneum. This membrane was simply tuberculous matter incorporated with the peritoneum; there had been tubercular disease before, and the patient suffered afterwards from tubercle elsewhere. In short, the affection which I discovered was tubercular peritonitis in a half quiescent condition; fluid full of cheesy matter had collected, and simulated a cystic tumour of uncertain origin. In another chronic tubercular case I found the parietal peritoneum converted into a thick, yellow, spongy membrane. Thus it is quite reasonable to suppose that Dr. Robinson's cyst wall " as thick as sole leather" was identical with the membranes which Cone and myself observed, as many others must have observed, in cases of undoubted tubercular peritonitis; in fact, it was tubercular peritoneum. The character of the cyst wall in these cases not only suggests that disease, but also compels us to put aside the supposition that the cyst represents an old, quiescent, serous perimetritis, such as Matthews Duncan and Sir John Williams have described. Hence the latter affection need not be discussed, although it is quite conceivable that a serous perimetritic cyst might puzzle an operator, and induce him to ascribe to it an allantoic origin.

7. From the foregoing objections we may conclude that these so-called "allantoic cysts" were really encysted dropsies due to chronic peritonitis, usually if not always tubercular. For encysted dropsy is often of tubercular origin, and liable to continue long after the subsidence of active tubercular disease, as the peritoneum is much damaged and hence has lost its power of rapid absorption. The fluid naturally tends to collect in 
Douglas's pouch, if that cavity be not effaced by adhesions, to rise forwards and to push the small intestines upwards. 'The parietal and visceral peritoneum bounding the effusion is very slow to return to its normal appearance. Recurrence of acute symptoms is always possible. When it occurs it is natural that the surgeon should explore, and when he has opened the abdomen the appearances are very puzzling. The peritoneum is completely altered, not only from its normal state but also from its familiar appearance when studded with recent tubercular deposit. As there was a great collection of fluid in Tait and Robinson's cases, and as tubercle, on their own admission, complicated more than one, I cannot help thinking that most if not all might be examples of old encysted dropsy due to tubercular disease. This explanation seems simpler than their own, which they admit to be theoretical, and Wutz's scepticism as to the urachal origin of large cysts must still be respected as eminently rational and never as yet refuted by clinical research or by surgical experience.

\section{The Surgery of Urachal Cysts.}

Experience teaches us that what are termed "cystic tumours of the urachus" in this communication may often be dissected away. with comparative ease (Tait, Douglas), whilst in other cases (Ill, Author) extirpation is impossible and incision and drainage answer well.

When a cyst has been dissected away from a large area of peritoneum it is best to trim the detached serous membrane, even if it appear unhurt. In Douglas's case it seems clear that sloughing of the flap was the cause of death. The peritoneum should be cut away until it is even with the cut edges of the parietes in the abdominal wound; then sutures can be applied as in an ordinary abdominal section. If, however, the peritoneum has been too extensively damaged to allow it to be neatly adjusted to the wound, it should be freely trimmed away 
up to the line where it joins the parietes. There is no danger in leaving a large area of the parietes, free from peritoneum, facing the peritoneal cavity. I have often had to face this condition after the removal of strongly adherent ovarian and other tumours, and never seen evil results. The parietal peritoneum is relatively more damaged in the case of a urachal cyst, as it is uniformly torn from its normal attachment; in ordinary abdominal operations bruising of its free surface is the usual injury, and more likely to be followed by oozing than sloughing.

The operator should never run risks through an extreme anxiety to leave the peritoneal cavity unopened.

Especial care must always be taken to ascertain the relations of the bladder to any cyst which might, by its position, be urachal. A sound should always be passed into the bladder by an assistant when the lower part of the cyst is being handled. Should a communication with the cavity of the bladder be discovered (Fig. 9), it is almost needless to say that it must be closed. The sutures should not include the vesical mucous membrane. Similar treatment is demanded if the bladder be torn during the separation of the cyst wall. Bearing in mind Wutz's anatomical researches, the operator must never forget that a valvular communication between the urachal canal and the bladder seems to be the normal condition when the canal is pervious (Fig. 5), nor must he forget that the wall of the bladder may be damaged at the operation and not give way till later on. Hence he must be on the look-out for urinary fistula for long after the patient's apparent recovery from the operation. Ill states that he once saw a case where a communication between the bladder and the cyst was overlooked or imperfectly obliterated. "The odour from the patient's sore was indescribable, and made life a torment to himself as well as his surroundings."

The abdominal wound should always be free, so as to extend as far downwards as the bladder and so far upwards 
as to pass well above the superior limits of the tumour. The surgeon can never proceed safely till he has made sure of the relations of the tumour. Their importance below is evident, above it is very necessary to examine the condition of the intestines and the peritoneum.

When the cyst wall cannot be detached it must be freely packed with gauze, or simply drained, as the case may be. The parietes must be closed from above downwards; the lower end of the wound being left open to allow of the removal of the tube or dressings. The tube must not be suffered to press on the bladder.

The enormous cyst-like cavity which Tait and Robinson explain by the allantoic theory is chiefly remarkable to the surgeon for the extreme perplexity which it causes him when he opens the abdomen for exploratory purposes. I have dwelt enough on this kind of cyst; whatever it may be, the authorities who have written on it aissuade us from any attempt to enucleate its wall. Fersonal experience makes me very disinclined to drain when I discover anything approaching tubercular peritonitis. That malady is best treated by free drying of the peritoneum and closure of the abdominal wound. Mr. 'l'ait's " circular drainage," conducted through the abdominal wound and also through Douglas's pouch, might be reasonable enough if a true urachal cyst, not tubercular, managed to bulge downwards and backwards behind the uterus, adhering to the lowest part of the pelvic peritoneum.

\section{Addendum.}

The Council of the Society have kindly permitted me to add two unpublished cases of cystic tumour of the urachus related by the President in the discussion which followed the reading of the above communication.

Mr. Bryant observed that, in the first case, ovarian dropsy was suspected. He continued: "In making my incision, however, through what I believed was the 
abdominal wall, I suddenly came down upon a cyst, which I opened, thinking I was dividing the peritoneum. To my surprise I came into the cavity of a cyst which discharged a quantity of fluid, not of the thick mucoid character with which we are familiar in ovarian disease, but of a thin serous nature, more or less blood-stained. I did not, however, think much of the fluid at the time, although I thought I had opened the cyst too soon. I then drained the cyst, and in following it upwards by way of its removal, to my surprise I found on tracing its posterior wall that I had not yet opened the peritoneal cavity. I consequently enlarged my opening a little upwards and came upon the peritoneum, the cavity of which I opened. I put in sponges to keep the intestines, \&c., well out of the way, and traced the peritoneum, which was reflected from above the umbilicus on to the posterior part of the cyst. I proceeded subsequently to take the cyst away, being all the time somewhat puzzled as to its relations. In dissecting it off $I$ found it was closely connected with the bladder, so much so that I was alarmed lest I should wound that organ. I therefore passed a sound into the bladder as a guide, but it was with considerable difficulty that I could separate the cyst from the fundus of the bladder. I succeeded, however, in doing so, and I was then surprised to find that the cyst fell into my hands; in fact, there was no pedicle, so that the cyst was obviously not ovarian. If I had possessed the knowledge which the author has placed before us to-night I have no doubt I should have made a thorough diagnosis. I remember also that the wall of the cyst was exceedingly thick and fibrous. The case eventually did well."

As the cyst lay in front of the peritoneum, was enucleable, yet closely connected with the bladder, there can be little or no doubt that it had developed from the urachus. Surgically, this case resembled Douglas's, Rotter's, and Tait-Teichelmann's, where the cyst could be and was enucleated. In the close relation of the cyst to the 
bladder this case recalls Rotter's and my own, as there was no difficulty in separating the cyst from the bladder in Tait's and Douglas's. The cyst in Mr. Bryant's case was not bilocular as in mine, nor complicated with cancer of the adjacent part of the bladder as in Rotter's.

Mr. Bryant's second case was undoubtedly an example of urachal cyst in a male. "In the early seventies, a man aged about thirty-five came under my care at Guy's Hospital complaining of great pain in the abdomen, with a swelling extending from the umbilicus to the pubes. He had a high temperature, and the tumour was extremely tender to the touch. To my mind it seemed certain that an abscess was forming behind the abdominal parietes. The bladder appeared to be all right. We drew off some urine which was quite natural, and we noticed at the time that the penis was not properly formed, there being slight hypospadias. On going into the history of the case the man told me that he had for years noticed a lump below the navel 'about the size of a small cocoa-nut.' It had never troubled him much, but was sometimes larger than at others. The patient, who was an intelligent man, thought it was the lump in question which was the seat of his trouble. By-and-by it became necessary to open it, and when I did so a most horribly fetid material escaped, which did not smell like urine. When the contents of the cyst were evacuated the cyst wall was found to be thick, and covered with lymph and sloughing tissue. After I had washed it out with iodine water and made it sweet, I still could not detect any smell suggestive of urine. I plugged the cyst with lint soaked in terebene oil, and put a few sutures into the large wound I had made. The plug was left in for some days, and on removing it no marked urinous smell could be detected. At the second or third dressing, however, the patient assured me that some urine had escaped from the wound, and close observation confirmed this statement. 'There was, however, no bladder complication; the wound subsequently contracted up, and in voL. LXXXI. 
a few weeks the patient made a good recovery. I, at the time, recorded that case as one of ulceration of the fundus of the bladder into the connective tissue, causing a perivesical abscess. I am sure now that it was one of urachal cyst."

This case is of the same type as George Morgan's and Dr. Newman's, representing an intermediate condition between urachal fistula and urachal cyst. As in Newman's the patient was a male adult, and as in his the communication with the bladder appears to have closed spontaneously. The forcing open of Wutz's valve through over-distension of the bladder may account for this transitional form of cyst. It would be well if some anatomist would further investigate the anatomy of this valvular fold at the vesical orifice of the urachus. We cannot feel sure that it is constant, yet if not constant it may none the less represent a normal condition, its absence being in that case abnormal. The surgeon dealing with a cyst of this kind must bear in mind Ill's experience of a secondary urinary fistula following an operation by another surgeon for urachal cyst.

\section{References.}

Cone, C., M.D.-“Encysted Dropsy of the Peritoneum secondary to Utero-tubal Tuberculosis," 'Bulletin of Johns Hopkins Hospital,' vol. viii, 1897, p. 91.

Douglas, Dr. R. (Nashville).- "Cysts of the Urachus," 'Amer. Journ. of Obstetrics,' vol. xxxvi, 1897, p. 472.

Duncan, J. Matthews.—' Clinical Lectures on the Diseases of Women, delivered in St. Bartholomew's Hospital,' 3rd edit., 1886, p. 227.

Freer, James A. - "Abnormalities of the Urachus," 'Annals of Surgery,' vol. v, 1887, p. 107.

Ill, Dr. Edward.- "Tumours of the Abdominal Wall," 'Transactions of the American Association of Obstetricians and Gynæcologists,' vol. v, 1892, pp. 238-243. 
Luschka, Prof. H.-"Ueber den Bau des menschlichen Harnstranges," 'Virchow's Archiv,' vol. xxiii, 1862, p. 1.

Morgan, George.— "A Dilated Urachus, accidentally opened while performing Abdominal Section,"' 'Lancet,' 1896, vol. ii, p. 1154.

Morris, Henry.- "Injuries and Diseases of the Abdomen," 'Ashhurst's International Encyclopædia of Surgery,' vol. v, 1885, p. 966. "A Clinical Lecture on the Surgical Affections of the Umbilicus;" ' Clinical Journal,' vol. i, 1892-3, p. 165.

Pratt, Reginald, M.D., and Bond, C. J., F.R.C.S.-“"Dilated Urachus treated by Incision and Drainage," ' Lancet,' 1890, vol. i, p. 898.

Robinson, F. Byron.- "Cysts of the Urachus (Congenital Cysts, Extra-peritoneal Cyst, or Dilatation of Functionless Ducts)," 'Annals of Surgery,' vol. xiv, 1891, p. 337. (The best of the more recent monographs. Lawson Tait's theory is very clearly demonstrated.)

Shattock, S. G.- "Imperforate Urethra in a Fœtus of about the Fourth Month." 'Trans. Path. Soc.,' vol. xxxix, 1888, p. 185.

Stanley, Edward.- "Polypous Excrescences of the Bladder," 'Trans. Path. Soc.,' vol. iii, 1852, p. 127.

Sutton, J. Bland.- 'Tumours, Innocent and Malignant,' 1893, p. 395 ; 'An Introduction to General Pathology,' 1886 , pp. $179-181{ }^{1}$

1 In this, the earlier of the two works by Mr. Sutton named in this table of references, it is noted that Mr. 'Tait believes that his large cysts originated in the urachus, and the reader is referred to that surgeon's paper in the 'Brit. Gynæc. Journ.,' vol. ii, “for further information.” With scientific caution, Mr. Sutton concludes, "For my own part, I believe the cysts are commoner than many suppose, but are unrecognised; and, what is more important, there is very good reason to believe that certain rure cases of cystic tumours, of large size, occasionally found between the peritoneum and the sheath of the rectus muscle, take origin in this structure." Mr. Sutton gives a good summary of the opinions of German anthorities on the compa. rative anatomy of urachal cysts. 
Tuit, Lawson.- "Twelve Cases of Extra-peritoneal Cysts," ' British Gynæcological Journal,' vol. ii, 1887, p. 328. Teichelmann and Lawson Tait.- "Congenital Cyst of the Urachus ; Abdominal Section; Recovery," 'Lancet,' 1888, vol. ii, p. 675 .

Thornton, J. Knowsley.- "Peritoneal Cysts with Blood Cyst of Left Ovary," 'Trans. Path. Soc.,' vol. xxix, p. 145.

Williams, Sir John, Bart.- "On Serous Perimetritis," 'Trans. Obstet. Soc.,' vol. xxvii, 1885, p. 169.

Wutz._-“Ueber Urachus und Urachuscysten," 'Virchow's Archiv,' vol. xcii, 1883, p. 387. (This monograph, the soundest on the subject, includes numerous references to early cases.)

(For report of the discussion on this paper, see 'Proceedings of the .Royal Medical and Chirurgical Society,' Third Series, vol. $x$, p. 142.) 


\section{DESCRIPTION OF PLATE VIII.}

A Case of Cyst of the Urachus; with Notes on Urachal and So-called "Allantoic Cysts" (Alban Doran).

FrG. 1.-Microscopical section of wall of cyst of urachus. (Author's case, $\times \frac{1}{8}$, Beck.) Plain muscle cells in longitudinal view are seen below. Above similar cells appear in transverse section, and some divided obliquely appear unusually large.

FIG. 2.-The urachus (after Luschka) from a man aged 50. Outer aspect of vesical mucous membrane $(a)$ is exposed; muscular coat $(b)$ turned back. The muscular sheath $(c)$ of the urachus, tendinous above $(d)$, has been divided longitudinally and turned back. The urachal canal $(e)$ is exposed, showing bulbous dilatations $(f)$. 

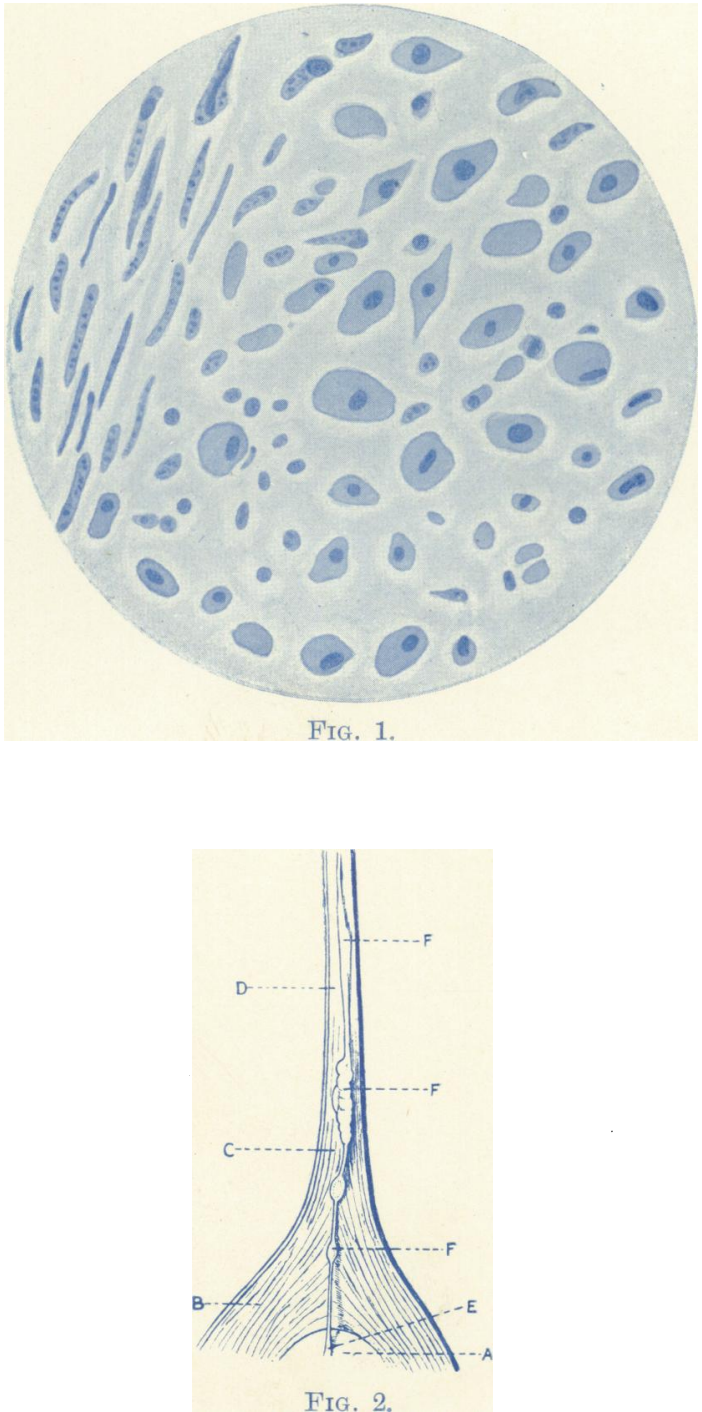

Printed and Engraved by Bale \& Danie/sson, Ltd., London. 


\section{DESCRIPTION OF PLATE IX.}

A Case of Cyst of the Urachus; with Notes on Urachal and So-called "Allantoic Cysts" (Alban Doran).

FiG. 3.-Longitudinal section of the normal urachus midway between the umbilicus and bladder, $\frac{1}{8}$ " obj., showing well-marked plain muscle cells seen at full length. (From a woman aged 45, subject to myoma of the uterus.)

FIG. 4.-Transverse section of the same (see fig. 3). Groups of plain muscle cells are seen divided transversely. White fibre, representing the tendinous part of the urachus, is abundant. The canal has entirely disappeared. ( $\left(\frac{1}{8} "\right.$ obj.) 


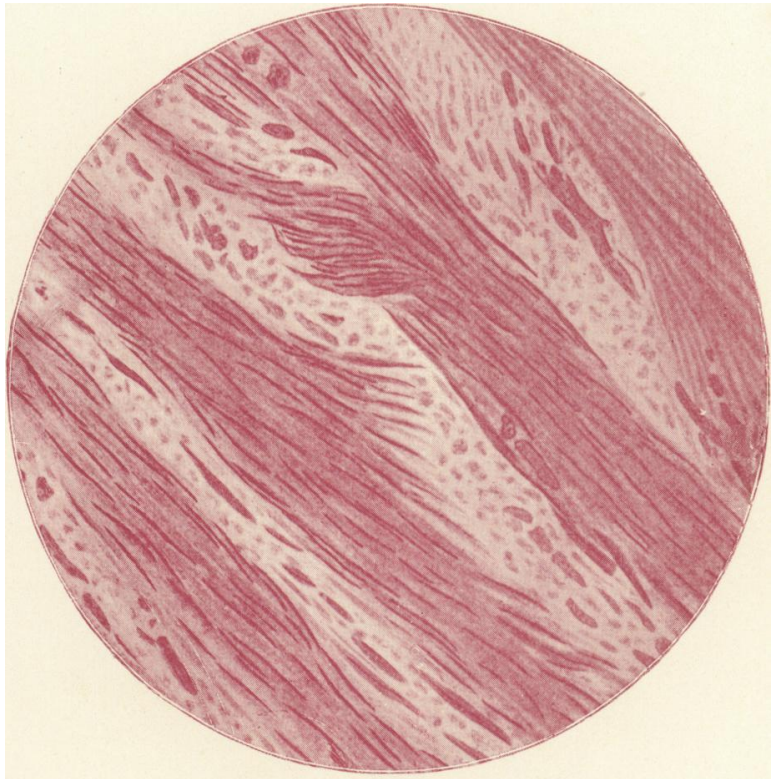

FIG. 3.

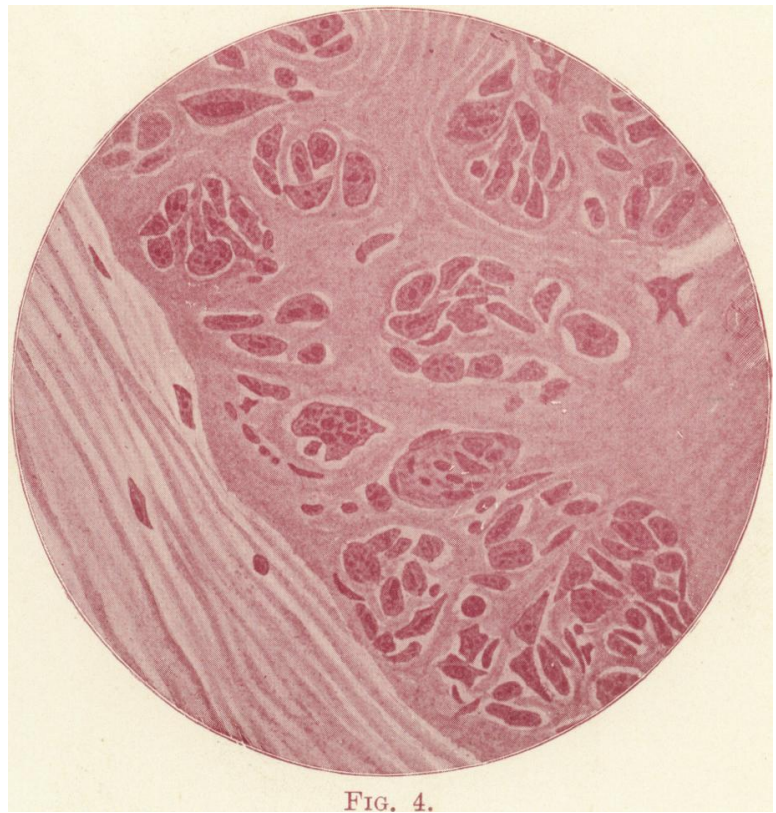

